\title{
Is there a body of evidence for the treatment of patients with Adolescent Idiopathic Scoliosis (AIS)?
} Hans-Rudolf Weiss

Address: Asklepios Katharina Schroth, Spinal Deformities Rehabilitation Centre, Korczakstrasse 2, D-55566 Bad Sobernheim, Germany

Email: Hans-Rudolf Weiss - hr.weiss@asklepios.com

Published: 3I December 2007

Scoliosis 2007, 2:19 doi:10.1186/1748-7161-2-19

This article is available from: http://www.scoliosisjournal.com/content/2/1/19

(C) 2007 Weiss; licensee BioMed Central Ltd.

This is an Open Access article distributed under the terms of the Creative Commons Attribution License (http://creativecommons.org/licenses/by/2.0), which permits unrestricted use, distribution, and reproduction in any medium, provided the original work is properly cited.
Received: 29 November 2007

Accepted: 31 December 2007

\begin{abstract}
Historically, the treatment options for AIS, the most common form of scoliosis are; exercises; inpatient rehabilitation; braces and surgery. While there is evidence in the form of prospective controlled studies that Scoliosis Intensive Rehabilitation (SIR) and braces can alter the natural history of the condition, there is no prospective controlled study comparing the natural history with surgical treatment.

One aim of the Scoliosis Society (SOSORT) should be; to help develop a body of research regarding the outcomes of conservative and operative treatment as well, and to highlight the problems of treatment indications in patients with AIS and other spinal deformities. Another aim is to help to improve the safety of patients who have surgery. By producing evidence-based information that can be used to develop guidelines that could aid both professionals and patients in making decisions about surgical and conservative options.

Although 'Scoliosis' is the official journal of the SOSORT and is the main forum for experts in the field of conservative management of patients with spinal deformities, there needs to be more wide spread attempt to develop a fuller body of evidence focussing on spine surgery as well.
\end{abstract}

\section{Editorial}

Today evidence based medicine (EBM) and evidence based practice (EBP) are valuable instruments in the decision making process of professionals in the medical field. Restrictions upon resources of social health care systems have lead to calls for greater efficiency and cost effectiveness of treatment programmes. Therefore good quality evidence studies providing the highest of research are necessary to evaluate effectiveness of treatments.

The Centre for Evidence Based Medicine (EBM) [1] provides guidelines to spread the knowledge about EBM and its use. There is a special hierarchy of evidence based knowledge:
1. Smallest evidence is provided by "expert opinion"

2. Case reports/case series

3. Un-controlled studies

4. Controlled studies

5. Randomized controlled studies (RCT) and

6. Meta analyses from RCT

The quality and types of evidence help to segregate research into levels. They are graded (IV [lowest] - I [high- 
est]) and from those levels recommendations for treatment are derived (Grade D [lowest] - Grade A [highest]).

Grade B recommendations for conservative treatment of scoliosis are justified. There are prospective controlled studies (level II) [2-4] and enough data from level III or IV, which are generally consistent [5] when taking into account studies from central Europe or Asia [6-9]. These levels of evidence seem not to have been reached in the United States [10,11].

Although randomised controlled trials (RCT's) provide the highest evidence the application of this study design is unrealistic for complex disorders like scoliosis. While pharmacological studies are the main field for RCT's until now no RCT on treatment outcomes for scoliosis is available.

In pharmacological studies one can easily standardise the treatments (drugs) to be investigated. Body weight of the patients and dosage of drugs can easily be measured [12].
Scoliosis on the other hand is not a uniform condition. Even the subset of patients suffering from Adolescent Idiopathic Scoliosis (AIS) appears to include multiple variations in curve pattern, maturity, curve stiffness and sexual differences all influencing the outcome of treatment [13]. Recently claims have been made for an RCT on bracing $[11,14,15]$, but the question remains to be answered; what brace, with what set amount of time, should be monitored and in which particular patient? It seems even difficult to define what exactly may be referred to as a "brace" as there is a wide variability of applications (Fig. 1). Treatment and subject treated are of such high variability that an RCT for bracing seems to be a very complex task.

Additionally to that, there is evidence on level II for the use of the Boston brace [3,4]. In the SRS multi-centre prospective controlled study [3] the survival analysis clearly has shown that the Boston brace was superior to observation only and to electrical stimulation. A long term controlled prospective follow-up has also provided evidence
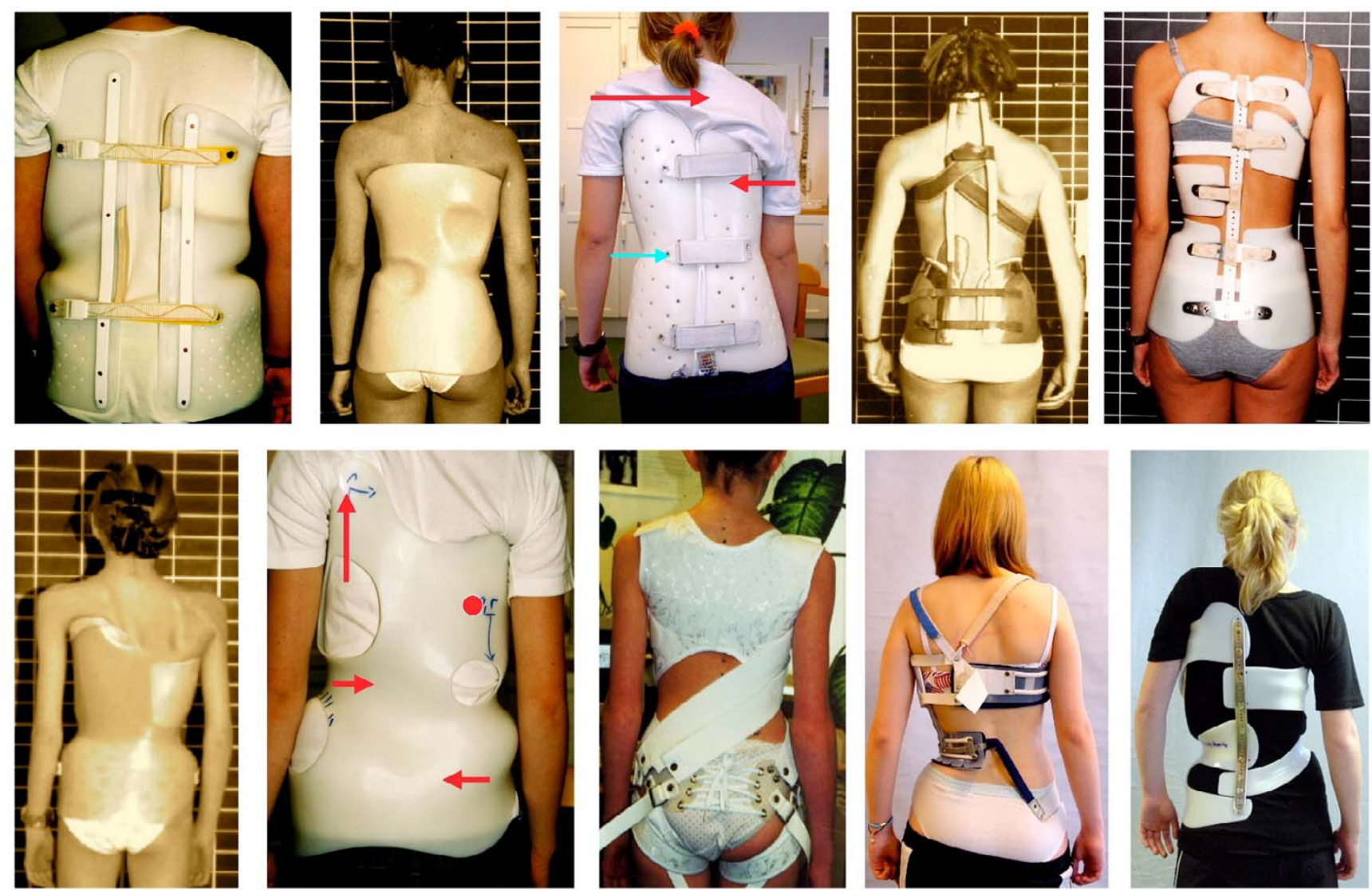

\section{Figure I}

Very many braces are on the market today making it difficult to design studies on that topic because of the high variability of standards applied. 
that the Boston brace efficiently stops curvature progression [4]. A Meta-analysis [16] clearly unveils that brace wearing time is one determinant for a successful outcome. But if the brace could not influence the curvature, why would the amount of time spent wearing the brace be an important issue?

In the light of this evidence already available, an RCT is not only a complex task but an unethical one. To allow growing patients to continue without conservative treatment (a control group) until nothing except surgical intervention can help them, is completely unethical. Especially when one considers the problems with surgery, such as; primary risks; a re-surgery rate, which might be higher than $30 \%$ in the long-term [17-19] and future complications [17]. This type of approach cannot be regarded as patient-oriented. This is why the SOSORT offers clinicians and scientists to take part in prospective controlled studies on bracing. Within this society there is a unique opportunity to test different bracing approaches against each other in order to find the "Best Practice" of bracing. This will enable clincians in the near future the opportunity to give their conservatively treated patients the best possible advice and offer the best possible treatment in a more standardized way. Research on living patients should only be done in order to develop a useful treatment, this is why we need to be able to measure brace quality. We know that in-brace correction and compliance are the two main determinants of outcome $[16,20,21]$. Therefore in-brace correction might serve as a measure for brace quality and compliance as a measure for quality of management. Efforts have to be made to improve both of these.

Unfortunately many studies on bracing, mainly coming from the US, do not attempt to find ways to improve this measurement $[10,11,14,22]$. Whether a brace works or not seems to depend upon the fate of the individual patient and not on brace quality. Some SRS Surgeons introduced the term "brace responder" or "nonresponder" [23] as if it was the patients fault when there is no successful outcome. No one attempts to explain why some patients are "non-responders" and with another brace the same patients are "responders" [24] (Fig. 2).

Examining the evidence at a deeper level in recent publications that claim RCT's on bracing $[11,14,15]$ :

Dolan et al. [11] have found a wide variation of surgical rates for a number of brace types worn 8 to 20 hours per day. The variation in the pool of selected data ranged from a surgical rate of $1 \%$ to $43 \%$. After calculating this data the authors concluded: "Based on the evidence presented here, one cannot recommend one approach [bracing] over the other [observation] to prevent the need for surgery in AIS " [11]
But there are four main weaknesses within this study; the subject (a brace) and the outcome parameter (rate of surgery), are components which are known to contain great ranges of variability and therefore, the only justified conclusion to be drawn from this study would be that 'rate of surgery' cannot be used to generate valid evidence.

Secondly, the authors set the inclusion and exclusion criteria in a way to enable the exclusion of studies that have presented a smaller rate of surgery and also those with the additional use of physiotherapy. Only one [6] of the four studies from outside the US [6-9] covering this topic is cited (but not included) in their paper, due to their specific choice of inclusion and exclusion criteria.

As Hawes clearly highlighted [25], a large number of papers from the US containing an undefined number of patients treated by physiotherapy do exist, even in natural history studies. But as physiotherapy historically has been recognized as 'no treatment' [25] they tend not to be considered within research reviews.

The third main problematic area within this study is that there is no mention of the correction effect of the braces used in this study. When brace quality is not assessed and in-brace correction is the only quality parameter applied, no conclusions about the use of bracing can be made. Braces from Europe have not been included in this paper, although they are of higher standards in terms of in-brace correction $[13,20,21,24,26]$.

The final and most significant weakness of this study is in relation to 'a need for surgery' for patients with AIS [11]. As signs and symptoms of scoliosis in AIS patients cannot be cured by surgery [27], there is no indication for surgery other than the cosmetic indication. As Goldberg pointed out in her paper [10], which can be viewed as the precursor of the paper by Dolan and Weinstein [11], surgery replaces one pathology (a curved spine) with another (a stiff spine). Therefore, there are no clinical indications for surgery in patients with AIS, when we are dealing with a relatively benign condition $[28,29]$ and when there is no proof that surgery changes signs and symptoms of scoliosis [27].

In another paper by Dolan et al [14], the subject of the 'professional' opinion concerning the effectiveness of bracing was investigated. As could have been expected, a high variability in opinions has been found in the group of surgeons and a small number of other professions. In this study a RCT on braces has also been postulated. One question remains to be answered: Is a surgeon automatically a 'professional' when bracing is the specialised subject? 

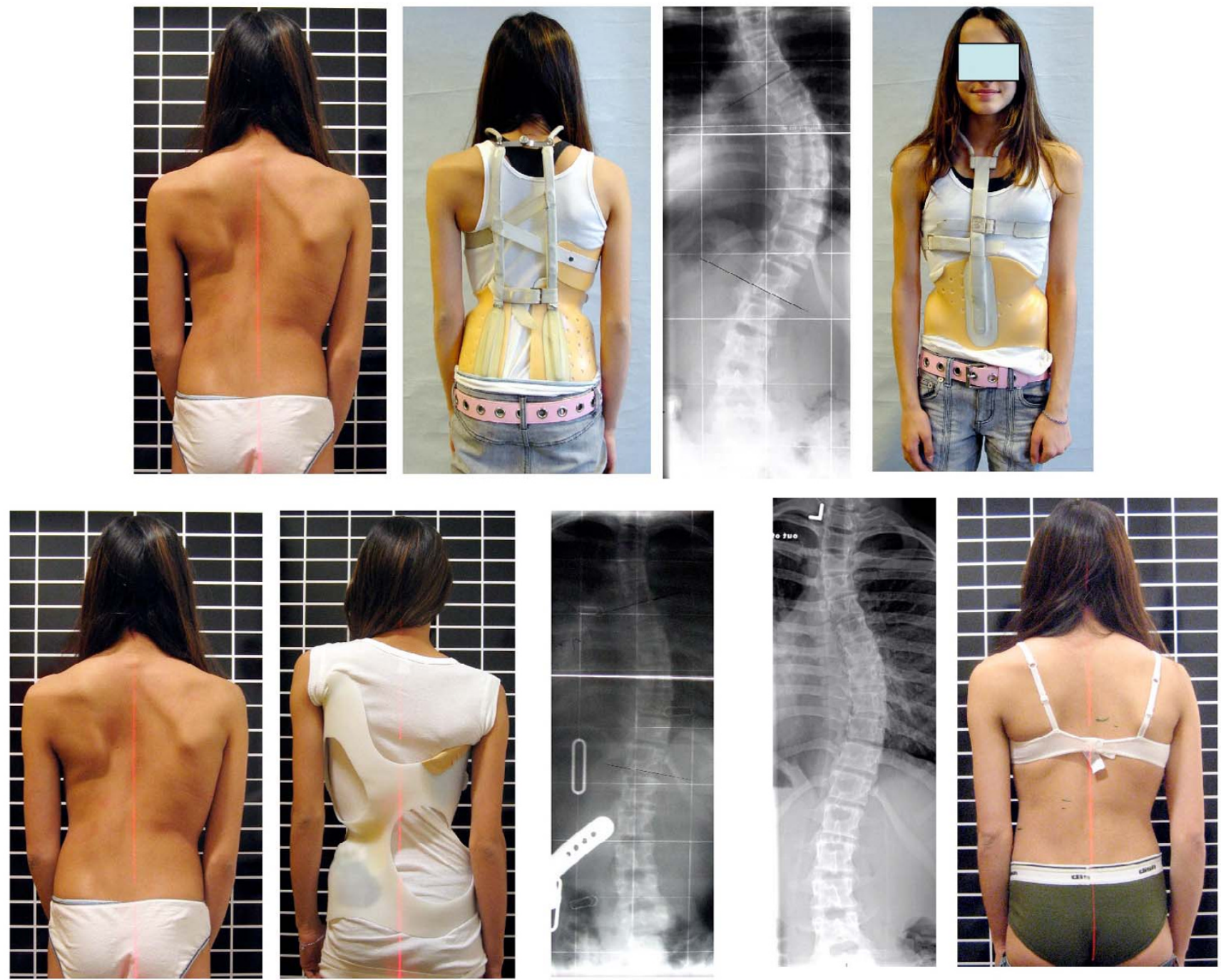

Figure 2

Patient with a thoracic curve of $56^{\circ}$ corrected to $53^{\circ}$ in her Milwaukee brace adjusted in North America (upper line). With this little correction effect one can predict no favourable outcome after this treatment. The question to be asked is: Is this patient a non-responder? In a brace of the Chêneau type she gained an in-brace correction down to $27^{\circ}$ and after 15 months of treatment she clinically improved and her curve (without the brace) was $36^{\circ}$ (lower line).

One might assume that the main benefit of surgery is correction. But when one realises that primary correction effects are not necessarily stable after surgery [30-40], not even in the first year and that neither back shape nor self esteem have been corrected to a satisfactory level by the surgical intervention [41] and that a balanced appearance of a patient is not necessarily the outcome of surgical intervention (Fig. 3 and 4), a more scientific basis remains to be desired on the true outcome after surgery.

With respect to surgery, there are no level II or level I studies to support the use of surgery in the treatment of AIS and as previously stated by Hawes [27], signs and symptoms of AIS cannot be changed by surgery.

But respect should remain for the psychological indication for surgery when a patient with AIS is unable to cope with the deformity.

The assumption that there is an indication for surgery', in spite of the known long-term risks [17-19,27], however should be made cautiously by those with an ethical responsibility to the patient as it seems that this lacks a scientific evidence base. 

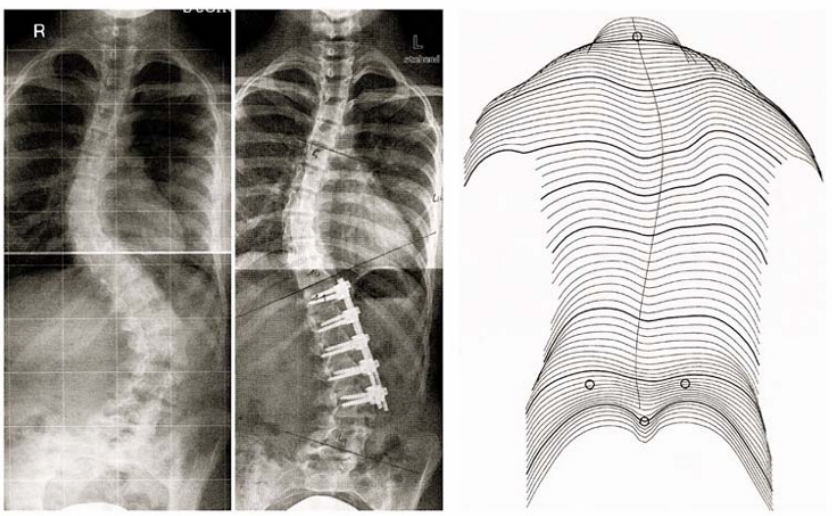

Figure 3

On the left X-rays before and after surgery and on the right clinical appearence after surgery. The patient is unbalanced. Due to the short instrumentation area there is a sharp angle at the junctional lumbo-pelvic area making it reasonable to assume that a reoperation will be necessary some day.

The long-term risks of surgical scoliosis treatment are not conclusively agreed upon. No studies are available to describe the aging operated patient with AIS, but when one considers that the 10 to 20 year risk for a re-operation (Fig. 5) may already be as high as 29\% [19], the real longterm risks have to be estimated at $>30 \%$ [27], it is this fact the patient should be informed of before consenting to undergo this procedure, as consent should always be an informed decision [18].

To help to develop the body of research regarding the outcome of surgery and to highlight the problems of treatment indications in patients with AIS and other spinal deformities we would like to open the Scoliosis Journal to papers that discuss surgical procedures.

One of our aims is to improve patients' safety in surgery by producing evidence-based information that can be used to develop guidelines that could aid both profession-

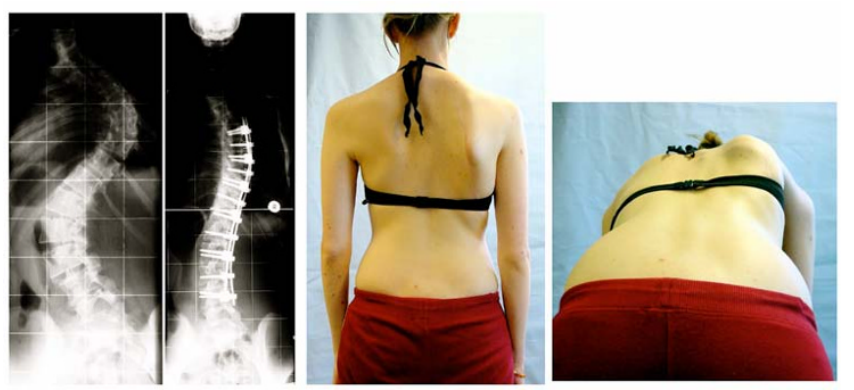

Figure 4

After surgery there is still a significant rib-hump visible.

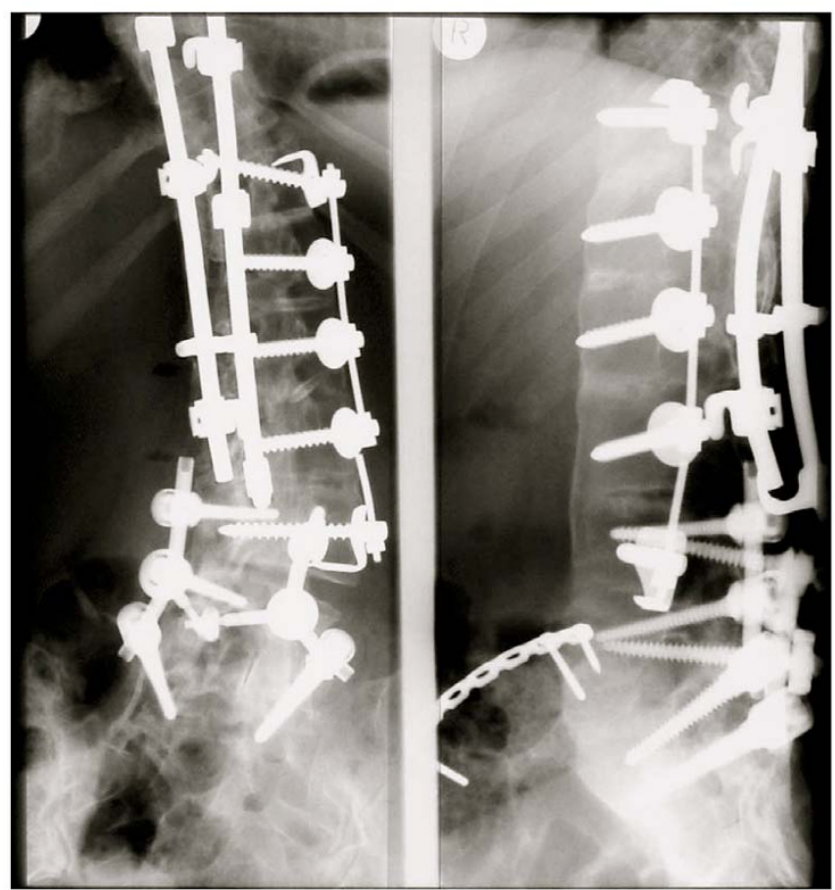

\section{Figure 5}

Condition after ventrodorsal reoperation. Stabilisation seemed necessary down to the sacrum. As there are no free segments below the fusion area problems may arise in the future.

als and patients in making decisions about surgical and conservative options.

Within this society we have well known spinal surgeons who are specialists in conservative management of scoliosis as well. This is why I am confident that to include papers with surgical content, is a step towards an equilibrated and balanced view on scoliosis management.

Tomasz Kotwicki, deputy editor in charge will oversee papers with surgical content from now on.

My very best wishes to my friend and colleague Dr. Tomasz Kotwicki, who surely is both: a dedicated physician and a remarkable pediatric spine surgeon.

\section{Acknowledgements}

The author is thankful to Deborah Goodall for copyediting this paper.

Written informed consent was obtained from the patients for publication of their cases.

\section{References}

I. Oxford Centre for Evidence-based Medicine, Levels of Evidence (May 200I) [http://www.cebm.net/?o=10II]

2. Weiss HR, Weiss G, Petermann F: Incidence of curvature progression in idiopathic scoliosis patients treated with scoliosis 
in-patient rehabilitation (SIR): an age- and sex-matched controlled study. Ped Rehab 2003, 6:23-30.

3. Nachemson AL, Peterson LE: Effectiveness of treatment with a brace in girls who have adolescent idiopathic scoliosis. A prospective, controlled study based on data from the Brace Study of the Scoliosis Research Society. J Bone Joint Surg Am 1995, 77(6):815-22.

4. Danielsson AJ, Hasserius R, Ohlin A, Nachemson AL: A prospective study of brace treatment versus observation alone in adolescent idiopathic scoliosis: a follow-up mean of 16 years after maturity. Spine 32(20):2198-207. 2007 Sep 15

5. Weiss HR: Rehabilitation of adolescent patients with scoliosis-what do we know? A review of the literature. Pediatric Rehabilitation 2003, 6(3-4): 183-94.

6. Rigo M, Reiter C, Weiss HR: Effect of conservative management on the prevalence of surgery in patients with adolescent idiopathic scoliosis. Pediatric Rehabilitation 2003, 6:209-2/4.

7. Maruyama T, Kitagawa T, Takeshita K, Mochizuki K, Nakamura K: Conservative treatment for adolescent idiopathic scoliosis: can it reduce the incidence of surgical treatment? Pediatric Rehabilitation 2003, 6(3-4):215-9.

8. Weiss HR, Weiss G, Schaar HJ: Incidence of surgery in conservatively treated patients with scoliosis. Pediatric Rehabilitation 2003, 6: III-8.

9. Edelmann P: Brace treatment in idiopathic scoliosis. Acta Orthop Belg 1992, 58(Suppl I):85-90.

10. Goldberg CJ, Moore DP, Fogarty EE, Dowling FE: Adolescent idiopathic scoliosis: the effect of brace treatment on the incidence of surgery. Spine 200I, 26:42-47.

II. Dolan LA, Weinstein SL: Surgical rates after observation and bracing for adolescent idiopathic scoliosis: an evidencebased review. Spine 32(19 SuppI):S9I-SI00. 2007 Sep I.

12. Hernandez D, Miquel R, Porrini E, Fernandez A, Gonzalez-Posada JM, Hortal L, Checa MD, Rodriguez A, Garcia IJ, Rufino M, Torres A: Randomized controlled study comparing reduced calcineurin inhibitors exposure versus standard cyclosporinebased immunosuppression. Transplantation 84(6):706-14. 2007 Sep 27

13. Weiss HR, Werkmann M, Stephan C: Correction effects of the ScoliOlogiC "Cheneau light" brace in patients with scoliosis. Scoliosis 2:2. 2007 Jan 26.

14. Dolan LA, Donnelly MJ, Spratt KF, Weinstein SL: Professional opinion concerning the effectiveness of bracing relative to observation in adolescent idiopathic scoliosis. J Pediatr Orthop 2007, 27(3):270-6

15. Goldberg CJ, Moore DP, Fogarty EE, Dowling FE: Scoliosis: a review. Pediatr Surg Int . 2007 Sep 22

16. Rowe DE, Bernstein SM, Riddick MF, Adler F, Emans JB, GardnerBonneau $D$ : A meta-analysis of the efficacy of non-operative treatments for idiopathic scoliosis. J Bone Joint Surg Am 1997 79(5):664-74.

17. Asher MA, Burton DC: Adolescent idiopathic scoliosis: natural history and long term treatment effects. Scoliosis I(I):2. 2006 Mar 31.

18. Sponseller PD, Cohen MS, Nachemson AL, Hall JE, Wohl ME: Results of surgical treatment of adults with idiopathic scoliosis. Bone Joint Surg Am 1987, 69(5):667-75.

19. Dickson JH, Erwin WD, Rossi D: Harrington Instrumentation and Arthrodesis for Idiopathic Scoliosis: A twenty-one year follow-up. J Bone Joint Surg Am 1990, 72:678-683.

20. Landauer $F$, Wimmer $\mathrm{C}$, Behensky $\mathrm{H}$ : Estimating the final outcome of brace treatment for idiopathic thoracic scoliosis at 6-month follow-up. Pediatric Rehabilitation 2003, 6(3-4):201-7.

21. Weiss HR: Standard der Orthesenversorgung in der Skoliosebehandlung. Med Orth Tech 1995, 5:323-330.

22. Castro FP Jr: Adolescent idiopathic scoliosis, bracing, and the Hueter-Volkmann principle. Spine / 2003, 3: | $80-5$.

23. Braun J: Identification of Progression Genes. Proceedings of the International Research Society of Spinal Deformities Meeting, Ghent 2006.

24. Weiss HR, Rigo M: The Chêneau concept of bracing - Actual standards. In SOSORT instructional course lectures Edited by: Grivas TB. IOS press in press.

25. Hawes MC: The use of exercises in the treatment of scoliosis: an evidence-based critical review of the literature. Pediatric Rehabilitation 2003, 6(3-4): 17|-82.
26. Hopf $C$, Heine ]: [Long-term results of the conservative treatment of scoliosis using the Cheneau brace]. Z Orthop Ihre Grenzgeb 1985, I 23(3):312-22.

27. Hawes M: Impact of spine surgery on signs and symptoms of spinal deformity. Pediatric Rehabilitation 2006, 9(4):3। 8-39.

28. Weinstein SL, Dolan LA, Spratt KF, Peterson KK, Spoonamore MJ, Ponseti IV: Health and function of patients with untreated idiopathic scoliosis: A $\mathbf{5 0}$ year natural history study. JAMA 2003, 289:559-567.

29. Haefeli M, Elfering A, Kilian R, Min K, Boos N: Nonoperative treatment for adolescent idiopathic scoliosis: a 10 - to 60 -year follow-up with special reference to health-related quality of life. Spine 3I(3):355-66. 2006 Feb I

30. Hill D, Raso VJ, Moreau K, Moreau M, Mahood J: Long-term followup of surgically treated AIS patients. Stud Health Technol Inform 2002, $91: 477-80$

31. Bettany J: Are Back Shape Changes Following Scoliosis Surgery Stable? A prospective 3 year follow-up of five different surgical procedures. Proceedings of the European Spinal Deformities Society. Birmingham 3I May - 3 June.

32. Helenius I, Remes V, Vrjonen T, Ylikoski M, Schlenzka D, Helenius M, Poussa M: Comparison of long-term functional and radiological outcomes after Harrington instrumentation and spondylodesis in AIS: a review of seventy-eight patients. Spine 2002, 27: $176-180$

33. Shapiro GS, Taira G, Boachie-Adjei O: Results of surgical treatment of adult IS with low back pain and spinal stenosis. A study of long term clinical radiographic outcomes. Spine 2003, 28:358-363.

34. Hamil CL, Lenke LG, Bridwell KH, Chapman MP, Blanke K, Baldus C: The use of pedicle screw fixation to improve correction in the lumbar spine of patients with IS. Is it warranted? Spine 1996, $21:$ I24I-1249.

35. Helenius I, Remes V, Yrionen T, Ylikoski M, Schlenzka D, Helenius M, Poussa M: Harrington and Cotrel-Dubousset instrumentation in AIS. Long term functional and radiographic outcomes. Journal of Bone and Joint Surgery 2003, 85-A:2303-2309.

36. Korovessis P, Filos KS, Zielke K: Effects of the combined VDSZielke and Harrington operation on the frontal rib cage deformity of double major curves in IS. Spine 1995, 20:106I-1067.

37. Wood KB, Transfeldt EE, Ogilvie JW, Schendel MJ, Bradford DS Rotational changes of the vertebral-pelvic axis following Cotrel-Dubousset instrumentation. Spine 1991, 16:S404-S408.

38. Wood KB, Schendel MJ, Dekutoski MB, Boachie-Adjei O, Heithoff $\mathrm{KH}$ : Thoracic volume changes in scoliosis surgery. Spine 1996, 21:718-723.

39. Wood KB, Olsewski J, Schendel M, Boachie-Adjei O, Gupta M: Rotational changes of the vertebral pelvic axis safter sublaminar instrumentation in AIS. Spine 1997, 22:5I-57.

40. Pratt RK, Webb JK, Burwell RG, Cole AA: Changes in surface and radiographic deformity after universal spine system for right thoracic adolescent IS. Is rib hump reassertion a mechanical problem of the thoracic rib cage rather than an effect of relative anterior spinal overgrowth? Spine 200I, 26: I778-1787.

4I. Bettany J, Partridge C, Edgar M: Topographical, Kinesiological and Psychological Factors in the Surgical Management of Adolescent Idiopathic Scoliosis. Stud Health Technol Inform 1995, I5:32|-326. 